\title{
Proyecto IniciaTIC 2020: aprender en casa a enseñar desde casa
}

IniciaTIC 2020 Project: Learning at Home to Teach from Home

Artículo de investigación | Research article

Fecha de recepción: 09 de noviembre de 2020

Fecha de aceptación: 25 de mayo de 2021

Fecha de disponibilidad en línea: noviembre de 2021

doi: 10.11144/Javeriana.m14.piac

José Luis Del Río-Fernández

joseluisdelrio@uma.es

UnIVERSIDAD dE MálAGa, EsPaña

(D) ORCID: https://orcid.org/0000-0001-9579-3530

Diana Priscila Saldaña-Gómez diana.saldana@unae.edu.ec

UnIVERSIDAd NACIONAL dE EDUCACIÓN, ECUADOR

D ORCID: https://orcid.org/0000-0001-6508-4362

Para citar este artículo | To cite this article Del Río-Fernández, J. L. \& Saldaña-Gómez, D. P. (2021). Proyecto IniciaTIC 2020: aprender en casa a enseñar desde casa. magis, Revista Internacional de Investigación en Educación, 14, 1-21. doi: 10.11144/Javeriana.m14.piac 


\section{Resumen}

Durante el confinamiento provocado por la pandemia del Covid-19, la implementación de docencia online mediante el uso de la tecnología educacional posibilita que las estudiantes de la carrera de Educación Inicial de la Universidad Nacional de Educación (UNAE) puedan realizar su correspondiente periodo de práctica pedagógica. Sobre esta realidad, se desarrolla un estudio de caso único de tipo indagatorio/exploratorio cuyo objetivo es identificar las fortalezas y debilidades encontradas a lo largo del proceso formativo. Los resultados demuestran que el análisis colectivo de las sesiones virtuales permite que las futuras docentes de preescolar vayan construyendo su propia identidad profesional en este singular contexto educativo.

\section{Palabras clave}

Tecnología educacional; práctica pedagógica; formación de docentes de preescolar

\section{Abstract}

During the confinement caused by the Covid-19 pandemic, the implementation of online teaching through the use of educational technology allowed the students of the Early Childhood Education program of the National University of Education (UNAE) to carry out their corresponding period of student practice. On this reality, a single investigative/ exploratory case study was developed whose objective was to identify the strengths and weaknesses found throughout the training process. Results showed that the collective analysis of the virtual sessions allows future early childhood educators to build their own professional identity in this unique educational context.
}

\section{Keywords}

Educational technology; teaching practice; preschool teacher education 
Descripción del artículo | Article description

En este artículo de investigación se presentan los resultados del Proyecto de Innovación Educativa IniciaTIC 2020,

desarrollado en la Universidad Nacional de Educación

(Azogues, Ecuador).

\section{Introducción}

La formación online a través de herramientas y plataformas virtuales no es el futuro, como se ha venido repitiendo en forma de mantra desde hace algunas décadas, sino el presente más inmediato y acuciante. Una realidad que se manifestó con toda su fuerza y plenitud a mediados de marzo del año 2020, cuando estalló la emergencia sanitaria mundial y las diferentes instancias gubernamentales decretaron un periodo de confinamiento en los hogares que se extendió durante varios meses para evitar el contagio y la propagación del llamado Covid-19, un coronavirus que ha hecho tambalear los cimientos de las sociedades del siglo XXI y que nos ha obligado a encontrar respuestas a una situación imprevista a la que nunca antes nos habíamos enfrentado. En este escenario de enorme incertidumbre y complejidad, el derecho a la educación de los niños y las niñas del Ecuador no podía quedar relegado y surgió la apremiante necesidad de que el profesorado, independientemente del nivel educativo en el que se desempeñara, hiciera un esfuerzo maratónico por adaptar su docencia a los entornos virtuales y aceptar el reto que supone intentar sacar el máximo provecho posible a las Tecnologías de la Información y la Comunicación, popularmente conocidas como TIC.

Partiendo de este planteamiento, en el seno de la Universidad Nacional de Educación (UNAE), los autores del presente escrito pusieron en marcha el Proyecto de Innovación Educativa IniciaTIC 2020 (figura 1), denominado así por tres motivos: en primer lugar, porque las protagonistas serían las estudiantes de noveno ciclo de la carrera de Educación Inicial de dicha institución; en segundo lugar, porque resultaba preciso, ahora más que nunca, iniciarse en el mundo de la enseñanza virtual para intentar dar respuesta a las necesidades educativas de los niños y las niñas del país (ya que la fecha en la que las escuelas ecuatorianas volverían a su funcionamiento habitual era todo un misterio); y en tercer lugar, porque las TIC se convertirían en el principal recurso para desarrollar el periodo de práctica pedagógica correspondiente al año 2020. 
Figura 1

Logotipo del Proyecto de Innovación Educativa IniciaT/C 2020

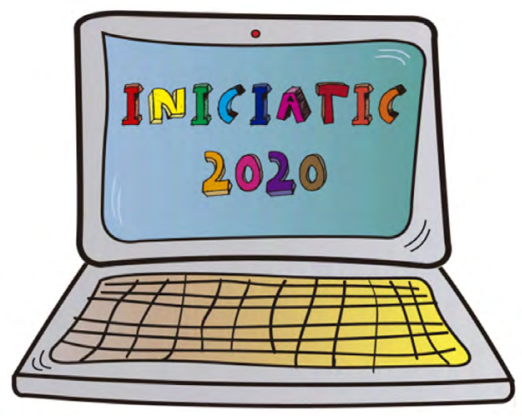

Nota. Infografía de elaboración propia (plantilla extraída de www.pngegg.com).

El propósito principal del proyecto era contribuir a la formación teórico-práctica de las estudiantes de la carrera de Educación Inicial mediante el uso de la tecnología educacional. Y para poder alcanzarlo, se les planteó un inusual reto: que emplearan las horas de práctica pedagógica en el diseño y la implementación de una serie de sesiones online - también conocidas como webinar-, dirigidas a niños y niñas de edades comprendidas entre 3 y 5 años, a las que los pequeños podrían acceder desde la seguridad y tranquilidad de sus hogares utilizando la aplicación informática ZOOM Cloud Meetings'.

Evidentemente, a raíz de los acontecimientos, tanto las asignaturas universitarias como la práctica pedagógica se realizarían mediante este sistema de videoconferencias, poniendo de relieve el desafío que teníamos por delante: aprender en casa a enseñar desde casa. En cualquier caso, se partió del convencimiento de que la reflexión conjunta y continua durante el curso académico permitiría a las estudiantes analizar las funciones desempeñadas y construir paulatinamente su identidad profesional en este contexto tan incierto y cambiante, contribuyendo a la formación de futuras docentes de preescolar con plena capacidad para investigar su propia práctica, independientemente de las circunstancias en las que esta se desarrolle (Del Río-Fernández, 2019; Marín-Suelves et al., 2021).

\section{Referentes conceptuales}

Este trabajo se apoya sobre la base de dos conceptos fundamentales: el primero se refiere a la disrupción que ha supuesto la migración forzosa hacia la docencia virtual para continuar desarrollando procesos de

1 Para conocer más, recomendamos visitar su página web: www.zoom.us 
enseñanza y aprendizaje en tiempos de pandemia (Serhan, 2020; Vera, 2021); el segundo, en la importancia crucial que tienen los periodos de práctica pedagógica para la formación de un alumnado que aspira a convertirse en profesional de la educación (Bolívar, 2019; Cortés-González et al., 2020; Zabalza, 2017). Y es que, en un principio, podría parecer algo inusual el hecho de poder conjugar virtualidad y práctica pedagógica cuando esta, por su propia naturaleza, se ha realizado siempre de manera presencial. De hecho, la valía principal de este periodo reside, precisamente, en la posibilidad que tienen los estudiantes de acudir a los centros educativos y asumir el rol docente en primera persona, interactuando con los niños en sus aulas ordinarias y tratando de sacar el máximo provecho posible a esta experiencia (Parra et al., 2021; Zabalza, 2017). Sin embargo, si por causas de fuerza mayor ya no es posible el acceso a los colegios, solo caben dos opciones: dejarse llevar por la indolencia y esperar a que la situación retorne a su estado original; o bien, plantear líneas de actuación alternativas que puedan resultar efectivas en un nuevo escenario.

Sea como fuere, lo cierto es que el cambio se produjo de modo drástico y repentino. En palabras de Crespo y Palaguachi (2020), "este país ha conocido la suspensión de actividades académicas por paros o situaciones de riesgo como sismos, pero jamás ha experimentado el teletrabajo como medio para continuar con la educación" (p. 296). Efectivamente, la traslación de la docencia presencial a la virtual se tornó como solución provisional a una problemática que requería la adaptación rápida a un nuevo contexto formativo, de modo que aprender a educar en la era digital (PérezGómez, 2012; Trujillo-Sáez et al., 2020) pasó a ser un imperativo impostergable, en lugar de una simple recomendación o llamada de atención al profesorado para que actualizara sus competencias profesionales.

Esta situación se tradujo en un paso forzoso que pilló desprevenidos a un buen número de docentes, que no poseían la experiencia ni las habilidades técnicas necesarias para ofrecer educación a distancia a través de plataformas digitales (Ruiz-Larraguivel, 2020). Sin embargo, existía el convencimiento social de que la educación no podía detenerse, a pesar de que los centros educativos permaneciesen cerrados. Así pues, tanto docentes como estudiantes acometieron la tarea de aprender de manera urgente, desde el aislamiento provocado por el confinamiento, los mecanismos necesarios para el desarrollo de una docencia $100 \%$ virtual.

Indudablemente, es de justicia reconocer que, en la mayoría de los casos, este aprendizaje se llevó a cabo por el consabido proceso de ensayoerror (tal vez con más errores que ensayos). Sin embargo, quizás sea el momento oportuno para reconocer también el "derecho a la equivocación" de todas las personas que se atrevieron a actuar en este contexto de forzada 
novedad y señalar la importancia que tiene el error como oportunidad de aprendizaje (Beck, 2019). Porque nadie nace sabiendo. Y como reza la cita atribuida al célebre poeta alemán Goethe (1749-1832), "la única persona que no se equivoca es la que no hace nada".

Ahora bien, los esfuerzos de las universidades por seguir adelante con los procesos formativos a pesar de la emergencia sanitaria no son algo exclusivo de Ecuador. Existen ejemplos de experiencias similares en otros países de nuestro entorno (Alatorre-Rojo et al., 2020; Atila, 2020; IISUE, 2020; Rappoport et al., 2020), las cuales han sido desarrolladas con mayor o menor acierto, atendiendo a unas circunstancias que, de entrada, no resultan fáciles. En este sentido, López-Ramírez y Andrés-Rodríguez (2020), a quienes reproducimos textualmente para respetar la honestidad de las declaraciones, exponen las principales barreras que dificultan la implementación de la docencia virtual:

En ocasiones, existe una sola computadora en el hogar que se comparte con otros miembros de la familia y muchos de los estudiantes no cuentan con un espacio para sus labores escolares. Además, al estar en casa, el tiempo de que disponen se fragmenta entre diversas actividades, tareas del hogar y el cuidado de otros familiares. A esto se suma que, aunque existe la creencia de que estos alumnos pertenecen a la generación tecnológica, muchos de ellos carecen de las habilidades necesarias para desarrollar actividades de aprendizaje de forma virtual, así como la autodisciplina que demandan estas modalidades, en un ambiente de estrés, incertidumbres y restricciones socioeconómicas derivadas de la pandemia. (p. 104)

Efectivamente, las dificultades estructurales y las brechas sociales, técnicas, tecnológicas y pedagógicas, han estado y siguen estando presentes en una zona del mundo en la que apenas el $45 \%$ de los hogares cuenta con conexión estable a internet (IESLAC, 2020), lo cual "es tanto como decir que solo uno de cada dos hogares está conectado" (p. 20). Pero no por ello hay que bajar los brazos ni caer en el desaliento. Como reza un antiguo aforismo popular: "cuando no hay razones para el optimismo, hay que buscar motivos para la esperanza". Y en este contexto de cuarentena, distanciamiento social y cierre de espacios físicos para evitar la propagación del virus, los datos revelan que el sistema de enseñanza por videoconferencia ha tomado un protagonismo relevante en las instituciones de educación superior como vía efectiva para aplicar el e-learning sincrónico (ChacónMedina , 2003; Reinoso-González, 2020). Así pues, a pesar de las dificultades, no queda más remedio que intentar continuar transmitiendo ilusión por el aprendizaje, aunque sea a través de una pantalla. 
No obstante, como ya se ha señalado anteriormente, una de las inquietudes más extendidas entre el alumnado universitario matriculado en carreras de educación era saber si la práctica pedagógica en los centros escolares acabaría suspendida dada la coyuntura. La preocupación existente era absolutamente comprensible, dada la enorme importancia que adquieren estos periodos formativos en la construcción identitaria de los futuros docentes, ya que se constituyen como los mejores escenarios posibles para aprender los entresijos de la profesión (Davini, 2015; Del Río-Fernández, 2019; Díaz-Quero, 2006; Zabalza, 2017).

De hecho, según las disposiciones oficiales recogidas en el Plan de Estudios de la carrera de Educación Inicial de la Universidad Nacional de Educación (UNAE), el alumnado de noveno ciclo debe cursar obligatoriamente una serie de horas de práctica pedagógica en contextos profesionales con el fin de que puedan dotar de sentido y utilidad los conocimientos teóricos adquiridos en las diferentes materias. En circunstancias normales, estas horas se habrían llevado a cabo en los pertinentes centros educativos, bajo la supervisión y el acompañamiento presencial por parte de las tutoras profesionales (docentes de aula), así como del profesorado universitario responsable de las asignaturas de Aproximación Diagnóstica y Cátedra Integradora, que asiste periódicamente a las instituciones para realizar las labores de seguimiento, asesoramiento y evaluación continua de las estudiantes. Sin embargo, a consecuencia de la pandemia, las escuelas de Ecuador dejaron de estar abiertas al público el día 12 de marzo de 2020. $Y$ tanto el personal docente como los niños y las niñas se vieron obligados a permanecer en sus casas durante un tiempo indefinido, cumpliendo con el estado de confinamiento dispuesto por el Gobierno del país. Ante esta situación, la única opción viable fue repensar las estrategias presenciales e intentar dar continuidad a los procesos formativos a través de las posibilidades que ofrecen las plataformas virtuales, entre ellas, ZOOM Cloud Meetings (Levy, 2020).

Este programa, de fácil instalación en cualquier ordenador, celular o dispositivo electrónico portátil, permite la realización de videoconferencias de duración limitada — cuarenta minutos en su versión gratuita — en la que pueden intervenir hasta cien participantes de manera simultánea. Además, contempla la opción de "compartir pantalla", de modo que la persona que organiza y dirige la reunión puede hacer público cualquier material que estime conveniente: imágenes, audios, videos, presentaciones en PowerPoint, etc., lo que ayuda, en buena medida, a dinamizar la comunicación y la interacción (Alatorre-Rojo et al., 2020; Chiñas-Palacios et al., 2019; SánchezMendiola, 2020; Serhan, 2020). 


\section{Metodología}

El objetivo de la experiencia investigativa era analizar la viabilidad de la docencia virtual para el desarrollo de la práctica pedagógica por parte del grupo de estudiantes de noveno ciclo de la carrera de Educación Inicial de la UNAE. Por consiguiente, el foco de estudio lo constituyó la revisión continua de las diferentes sesiones online diseñadas por dichas estudiantes y el análisis reflexivo de las fortalezas y debilidades encontradas.

El trabajo se abordó desde un enfoque metodológico de carácter cualitativo que se materializó en un estudio de caso único de tipo indagatorio/ exploratorio (Álvarez y San Fabián, 2012; Angulo y Vázquez, 2003; Stake, 2020). El argumento que justificó esta decisión es que no se quería validar ninguna hipótesis previa ni traducir en cifras numéricas unos resultados que, evidentemente, no tenían por qué ser susceptibles de generalización a otros contextos formativos. Siguiendo a Bisquerra (2016), el estudio de caso es una estrategia de investigación empírica que se erige como opción metodológica alternativa a la experimentación y a los estudios muestrales, cuyos resultados se amparan en la representatividad estadística. Efectivamente, los estudios de caso no siguen la lógica de la repetición o la replicación directa en otros escenarios, porque lo que prima es la singularidad y el deseo explícito por parte de los investigadores de analizar un fenómeno concreto surgido en el seno de un contexto específico (Chavarría-Navarro et al., 2004; Martínez-Carazo, 2006).

La estrategia utilizada para la recogida de información fue la observación participativa, y los instrumentos empleados fueron el registro en video de las diferentes sesiones, las anotaciones en el diario de campo y una encuesta. Cabe señalar que, para aportar rigor, fiabilidad y validez al estudio, todos los datos obtenidos fueron sometidos a un exhaustivo proceso de triangulación (Cisterna-Cabrera, 2005; Okuda y Gómez-Restrepo, 2005). Por consiguiente, las informaciones recabadas mediante los instrumentos citados se completaron con las declaraciones procedentes de una serie de entrevistas a las tutoras profesionales, a las directivas de cada uno de los centros de prácticas y a las familias, para conocer el nivel de satisfacción de todas las personas implicadas en el proyecto y cotejar las impresiones resultantes.

\section{Descripción de los participantes}

El grupo de noveno ciclo de la carrera de Educación Inicial de la UNAE estaba compuesto únicamente por once estudiantes: diez mujeres y un solo varón (de ahí que los autores del escrito hayamos decidido utilizar el femenino genérico para referirnos al grupo). Es preciso reconocer que 
este factor supuso una enorme ventaja a la hora de desarrollar el proyecto IniciaTIC 2020, y es que el hecho de poder trabajar con un número reducido de estudiantes facilita mucho el seguimiento de las acciones educativas y el acompañamiento constante en el aprendizaje. Lógicamente, cuanto mayor es la cantidad de alumnos y alumnas, mayores son las dificultades para ejercer la labor de tutorización, ya sea en formato virtual o presencial. Por suerte, las condiciones fueron idóneas para la revisión sistemática del proceso formativo.

Las once estudiantes desarrollaron su periodo de práctica pedagógica en dos centros educativos fiscales: el CEl Rita Chávez de Muñoz y el CEl de Innovación UNAE, ubicados en Cuenca y Chuquipata (Azogues-Ecuador), respectivamente. La distribución por centro y aula queda recogida en la tabla 1:

Tabla 1

Distribución de estudiantes para realización de la práctica pedagógica

\begin{tabular}{l|l|l|c|c}
\hline Ciudad & Institución & Grados & $\begin{array}{l}\text { Número } \\
\text { de tutoras } \\
\text { profesionales }\end{array}$ & $\begin{array}{l}\text { Número de } \\
\text { estudiantes } \\
\text { practicantes }\end{array}$ \\
\hline \multirow{2}{*}{ Cuenca } & CEl Rita Chávez & Inicial 2 "A" & 1 & 2 \\
\cline { 3 - 5 } & de Muñoz & Inicial 2 "B" & 1 & 2 \\
\cline { 3 - 5 } & Inicial 2 "C" & 1 & 1 \\
\cline { 3 - 5 } & Inicial 2 "D" & 1 & 1 \\
\hline \multirow{2}{*}{ Azogues } & CEl de Innovación & Inicial 1 "A" & 1 & 2 \\
\cline { 3 - 5 } & UNAE & Inicial 2 "A" & 2 & 2 \\
\hline
\end{tabular}

Nota. La tabla ha sido extraída de los diarios de campo de los investigadores.

Contando siempre con la ayuda de las docentes de aula, las estudiantes atendieron durante 9 semanas a un total de 110 infantes de edades comprendidas entre 3 y 5 años, pertenecientes al Subnivel Inicial 2, aunque cabe señalar que el número de niños y niñas que accedían a las videoconferencias era variable en cada sesión, ya que no todas las familias podían permitirse la conexión diaria a internet. Además, los problemas de conectividad eran frecuentes en muchos hogares, lo que originaba que la comunicación no fuese fluida en algunos momentos.

\section{Descripción de las fases del proyecto}

La ejecución del IniciaTIC 2020 se programó atendiendo a cuatro fases o momentos principales, y cada uno de ellos se constituyó como una realidad susceptible de análisis y reflexión mediante la pertinente recogida de información: 
- Fase 1: Creación de vínculos entre universidad, escuela y familias. La primera fase consistió en establecer los contactos previos con las directivas de los centros educativos asignados desde la UNAE, para presentar el proyecto y organizar de manera adecuada el periodo de práctica pedagógica, acordando los días en los que las estudiantes podrían llevar a cabo sus intervenciones. Posteriormente, estos encuentros se hicieron extensivos también a las tutoras profesionales y a las familias, a quienes se les explicó la iniciativa y se les invitó a participar de manera activa, acompañando a sus hijos e hijas en el transcurso de las videoconferencias.

- Fase 2: Selección, diseño y elaboración de materiales. La segunda fase consistió en la búsqueda y selección, por parte de las estudiantes, de recursos educativos que pudiesen resultar de utilidad para la ejecución de las sesiones virtuales: videos, juegos, canciones, poesías, adivinanzas, trabalenguas, actividades, imágenes, etc. Con ellos, se procedería al posterior diseño de materiales para compartir con los niños y niñas (infografías, diapositivas, presentaciones en PowerPoint, etc.). Por supuesto, para esta fase contaron con el asesoramiento y el apoyo del profesorado universitario que, a través de tutorías organizadas en el marco de sus respectivas asignaturas, ofrecieron recomendaciones generales y contribuyeron a supervisar el proceso.

- Fase 3: Planificación del acompañamiento. La tercera fase consistió en la elaboración de un calendario semanal y de un horario específico para el desarrollo de las sesiones, procurando, en la medida de lo posible, que las intervenciones de las estudiantes estuviesen en consonancia con las programaciones planificadas por las docentes de aula, quienes — como ya se ha indicado — hacían las veces de tutoras profesionales. De esta manera, la práctica pedagógica no interferiría con el trabajo previsto con los niños y las niñas durante el confinamiento. A su vez, se acordó el contacto directo con las familias mediante correo electrónico y mensajería por WhatsApp, en aras de favorecer el trabajo conjunto. Los canales de comunicación se inauguraron mediante el envío de una carta formal de presentación y de un video explicativo sobre cómo instalar la aplicación ZOOM Cloud Meetings en los dispositivos electrónicos que fuesen a utilizar los pequeños.

- Fase 4: Desarrollo de las sesiones. La siguiente fase consistió en la implementación en sí de las sesiones virtuales, a lo largo de las nueve semanas de práctica pedagógica. Y aunque la participación 
de las estudiantes en los grados correspondientes fue continua durante todo este periodo, los días y horarios concretos de intervención fueron pactados de antemano con las tutoras profesionales, para evitar caer en la improvisación o el repentizado. Según las características de las actividades diseñadas, y atendiendo a los contenidos que se tenía previsto abordar en cada jornada, las estudiantes decidieron trabajar a la vez con todo el grado asignado, o bien dividirlo en grupos reducidos, estableciendo horarios diferentes para la atención de cada grupo (figura 2).

Figura 2

Sesión virtual en pequeño grupo

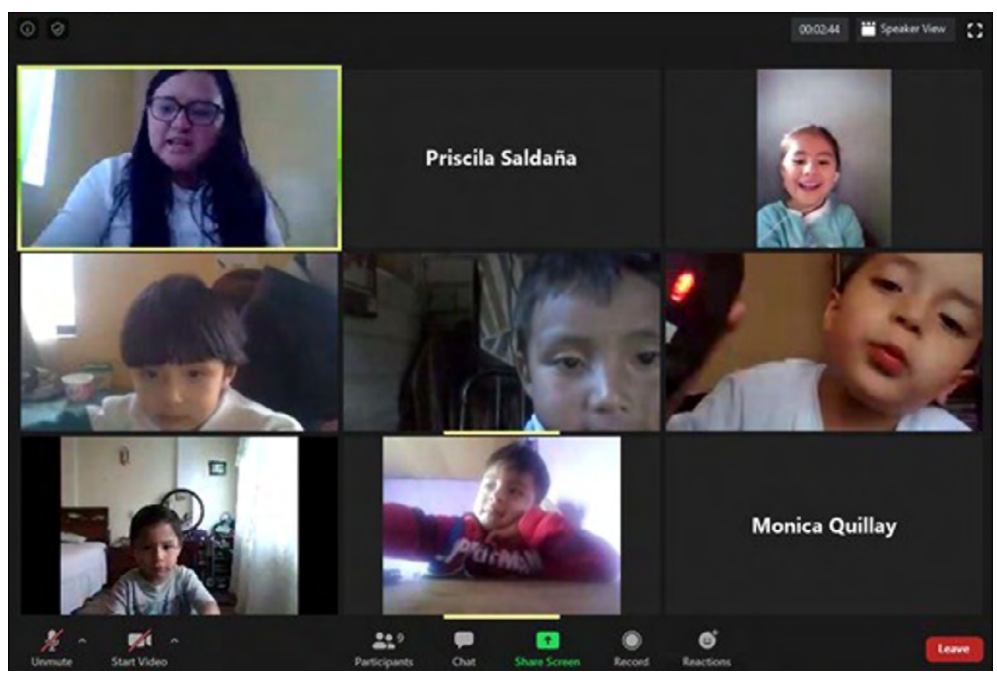

Nota. La imagen recoge un momento del trabajo desarrollado por una de las estudiantes durante una sesión organizada para un grupo reducido de niños y niñas (la evidencia ha sido extraída de los diarios de campo del profesorado. Los investigadores cuentan con los permisos paternos para registrar y difundir imágenes de sus hijos e hijas con fines investigativos 0 académicos).

En el caso de las estudiantes que decidieron realizar la práctica pedagógica en parejas, también se barajó la posibilidad de que atendieran de manera simultánea a un número de infantes determinado y se alternaran los roles semanalmente para que ambas pudieran interactuar con todo el grado, aunque no fuese al mismo tiempo. El planteamiento de las diferentes dinámicas de trabajo reveló que la cantidad de niños y niñas por sesión es un factor que debe ser considerado en el diseño y la implementación de la docencia virtual, ya que resulta muy complicado captar la atención de todo el grupo y trabajar de manera ordenada si no se ha previsto con antelación la cantidad de personas que va a estar al otro lado de la pantalla (figura 3). 
Figura 3

Sesión virtual con un grupo de clase al completo

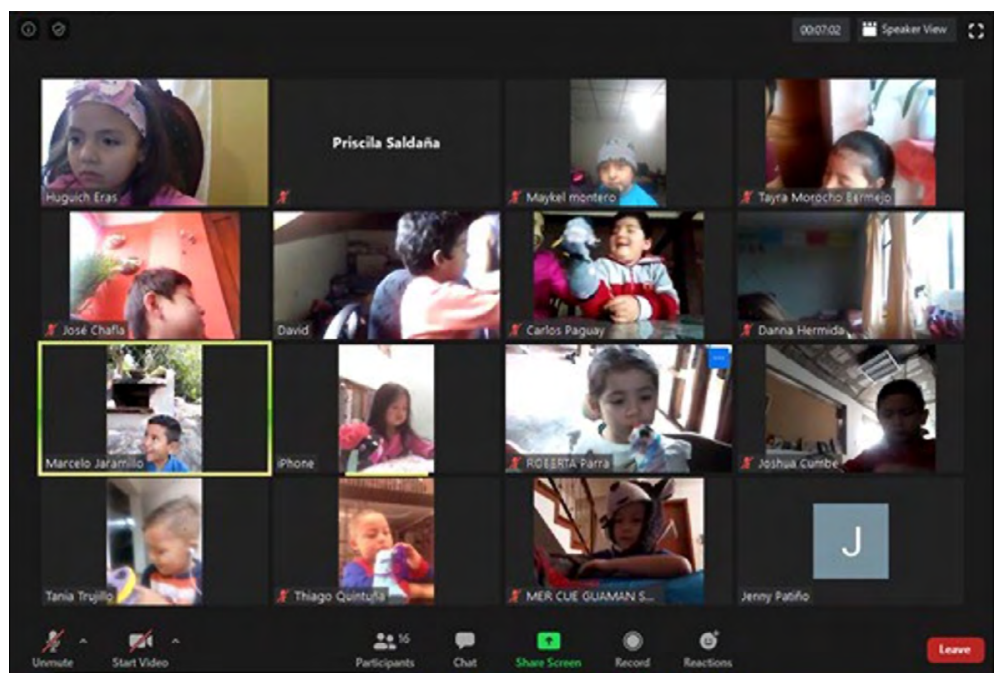

Nota. La imagen muestra la dificultad que tienen las estudiantes para mantener el interés de un grupo numeroso de niños y niñas durante el desarrollo de una sesión, debido a la gran cantidad de estímulos que aparecen en la pantalla (la evidencia ha sido extraída de los diarios de campo del profesorado. Los investigadores cuentan con los permisos paternos para registrar y difundir imágenes de sus hijos e hijas con fines investigativos o académicos).

- Fase 5: Análisis conjunto. Una última fase del proyecto se ejecutó de manera paralela al desarrollo de las sesiones por parte de las estudiantes y consistió en el análisis de las mismas. En este sentido, el profesorado universitario consideró pertinente aprovechar que el programa ZOOM contempla la opción de grabar las videoconferencias y descargarlas en formato video, de modo que estas quedan archivadas en los dispositivos y es posible volver a reproducirlas las veces que resulte necesario, para solicitar a las estudiantes dichas grabaciones. Desde una óptica formativa, no cabe duda de que esta opción multiplicaba las posibilidades de aprendizaje, ya que cada una de las sesiones implementadas podía ser sometida a revisión, análisis y mejora mediante la estrategia metodológica de la Lesson Study (Del Río-Fernández, 2021; Elliott, 2015; Pérez-Gómez y Soto, 2011; SotoGómez et al., 2019). Esta dinámica de trabajo, aplicada en el marco de las asignaturas universitarias, procuró el intercambio de información entre las estudiantes y la construcción colectiva de un saber docente, surgido, precisamente, del análisis colectivo de las sesiones.

\section{Discusión de resultados}

Una vez concluido el proyecto IniciaTIC 2020, los investigadores procedieron a organizar toda la información recopilada y a examinarla desde una 
perspectiva crítica para averiguar si la experiencia había resultado beneficiosa para las estudiantes. Los resultados obtenidos fueron los siguientes:

- A pesar del confinamiento provocado por la situación de pandemia, todas las estudiantes de noveno ciclo lograron cumplir con éxito las horas de práctica pedagógica exigidas para poder completar su formación universitaria, según las disposiciones establecidas en el plan de estudios de la carrera. Además, enriquecieron su proceso formativo con la experiencia profesional y personal que supone enfrentarse al reto de aplicar la virtualidad en la educación preescolar, algo para lo que nadie las había preparado anteriormente.

- Algunas de las acciones virtuales realizadas han sido: lectura de cuentos y poesías, canciones, bailes y ejercicios de expresión corporal, juegos con materiales de construcción u objetos del hogar, conversatorios sobre experiencias cotidianas, elaboración de manualidades, implementación de ambientes de aprendizaje en casa, ejercicios para el desarrollo del lenguaje, ejercicios para la expresión emocional, creación de títeres, desarrollo de experimentos, etc. Todas las actividades propuestas por las estudiantes estaban en línea con los ejes y los ámbitos de aprendizaje establecidos en el Currículo de Educación Inicial del Ecuador. Además, en algunos casos, las estudiantes elaboraron videos tutoriales de corta duración, con instrucciones y recomendaciones para que las familias pudieran acompañar a los pequeños en su aprendizaje, lo que contribuyó a aumentar sus competencias en el manejo de las TIC.

- La implicación y la colaboración activa por parte de las estudiantes durante el periodo de práctica pedagógica dio lugar a la creación de verdaderas sinergias en los diferentes grados. Las correspondientes tutoras profesionales guiaban las acciones realizadas, aprobaban las planificaciones semanales y sugerían actividades para hacer 
más atractivas las sesiones. Por su parte, las estudiantes asistían diariamente a las videoconferencias organizadas por las tutoras y apoyaban en las actividades programadas, proponiendo dinámicas o ejercicios complementarios.

- A pesar de que el proceso se ha llevado a cabo a través de una pantalla, y esto ha impedido disfrutar del "calor humano" que caracteriza las acciones educativas presenciales, lo cierto es que ha existido en todo momento una buena interacción entre los participantes: estudiantes, alumnos, familias, tutoras profesionales y profesorado universitario. La comunicación también ha sido constante, gracias a recursos alternativos como la mensajería por WhatsApp, el intercambio de correos electrónicos y las llamadas telefónicas.

- Las estudiantes reconocieron que la organización previa y el trabajo en grupo fueron factores que les permitieron llevar a cabo actividades novedosas, lúdicas e innovadoras, muy alejadas de las tradicionales fichas de trabajo que suelen ser habituales en los centros de educación inicial. Además, varios grupos trabajaron directamente con los padres y las madres, ya que también se encontraban en situación de confinamiento. Esta relación tan estrecha ente familias y estudiantes nunca se había producido en los anteriores periodos de práctica pedagógica. Ambos colectivos manifestaron su satisfacción al respecto.

- Al asumir el rol de anfitrionas durante los encuentros, las estudiantes contaban con la posibilidad de activar y silenciar los micrófonos de los participantes, de modo que se procuraba un cierto orden a la hora de tomar y ceder la palabra. Además, cuando se precisaba de algún material específico para el desarrollo de las sesiones (papel, pegamento, tijeras, lápices de colores, etc.), este era solicitado con anticipación a las familias a través de las vías de contacto establecidas, de modo que los infantes contaban con los recursos necesarios para que las actividades previstas inicialmente pudieran realizarse sin problemas, ya fuese de manera autónoma o en compañía de un adulto.

- Como promedio, más de cien niños y niñas accedieron a los encuentros virtuales con ayuda de sus familiares, quienes, por lo general, solían permanecer a su lado mientras transcurría la sesión. Este hecho, sumado a la colaboración prestada a la hora de facilitar los materiales oportunos, denotó la existencia de un alto grado de interés, compromiso y responsabilidad por parte de las familias en la educación de sus hijos e hijas, así como de la buena acogida que tuvo el proyecto. 
- Entre los dos centros de prácticas, se llevaron a cabo un total de 102 sesiones virtuales. Por supuesto, algunas salieron mejor que otras. Y si bien es cierto que "una videoconferencia que no logre la motivación no generará aprendizaje significativo" (Reinoso-González, 2020, p. 61), también lo es que las expectativas no siempre coinciden con la realidad, y eso no es motivo para desmerecer el esfuerzo puesto en la tarea; más bien, todo lo contrario. Las estudiantes tenían por delante el desafío de captar la atención de los pequeños durante el tiempo que duraran las videoconferencias y presentar materiales que resultasen lo suficientemente atractivos para que los procesos de enseñanza-aprendizaje se hicieran efectivos. Hicieron lo que pudieron y, en la mayoría de los casos, lo hicieron bien (figura 4).

Figura 4

Ejemplo de materiales educativos utilizados durante las sesiones virtuales

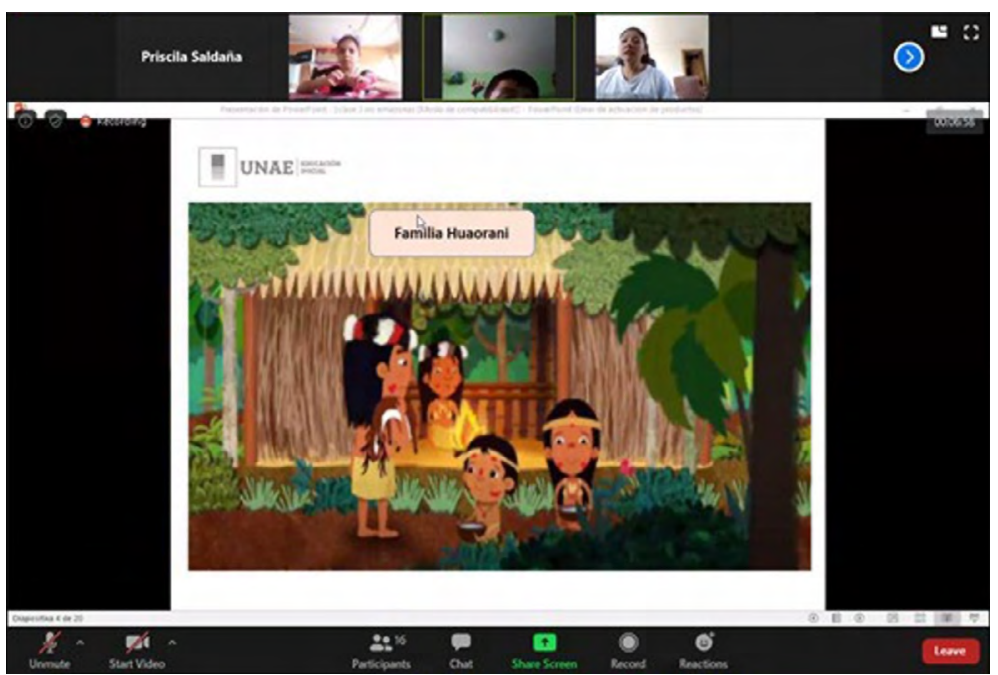

Nota. Las estudiantes elaboraban sus propios recursos o seleccionaban materiales didácticos disponibles en la red y lo adaptaban según los propósitos establecidos para cada sesión (la evidencia ha sido extraída de los diarios de campo del profesorado).

- El análisis colectivo de las sesiones diseñadas e implementadas durante la práctica pedagógica se constituyó como una valiosa estrategia de mejora continua. Y es que, aunque el profesorado universitario accediera a las videoconferencias y acompañara a las estudiantes mientras desarrollaban sus sesiones, no intervenía en ellas en ningún momento, permitiéndoles que ejecutaran sus planificaciones con total libertad y autonomía. Posteriormente, se realizaba una retroalimentación, que ayudaba a detectar las fortalezas y las debilidades encontradas. De esta manera, las sesiones iban mejorando 
progresivamente y los "errores" cometidos, lejos de verse con un carácter punitivo, se constituían más bien como una valiosa fuente de aprendizaje.

- Durante el periodo comprendido entre marzo y agosto, se realizaron siete Lesson Study que se constituyeron como eje de trabajo para las asignaturas universitarias relacionadas con el análisis de la práctica pedagógica (Catedra Integradora y Aproximación Diagnóstica). De hecho, la prueba de evaluación de estas materias consistió en la revisión por pares de las sesiones diseñadas, implementadas y registradas en video. De este modo, las estudiantes pudieron valorar la planificación y el desarrollo de las videoconferencias realizadas por sus iguales. Los resultados obtenidos en las calificaciones finales demuestran que esta actividad propició la reflexión crítica, la autoevaluación y el aprendizaje colaborativo. Además, es evidente que este ejercicio las preparó para su futuro desempeño laboral.

- Al culminar la práctica pedagógica, se aplicó una encuesta a las estudiantes, con la finalidad de conocer sus impresiones sobre una experiencia que podría definirse como única y sin precedentes. No solo era la primera vez que asumían el rol docente en una modalidad de enseñanza virtual, sino que, además, estas prácticas tan particulares serían las últimas de su trayectoria académica. Por este motivo, sus opiniones resultaban de vital importancia para valorar el proyecto. La encuesta constaba de cinco preguntas de respuesta abierta y de cinco ítems con los que las estudiantes debían mostrar su acuerdo o desacuerdo atendiendo a una escala Likert (1-5), en la que el 1 significaba "en total desacuerdo" y 5 "absolutamente de acuerdo". Los resultados obtenidos se detallan a continuación:

- El 100 \% de las estudiantes consideró "muy útil" el apoyo brindado tanto por las tutoras profesionales como por el profesorado universitario a cargo de la tutorización de las prácticas pedagógicas. A pesar de la falta de presencialidad física, reconocieron que el acompañamiento fue constante.

- Las principales debilidades encontradas durante la aplicación de la docencia virtual fueron: el desconocimiento general de las familias sobre el uso de las TIC, la falta de autonomía por parte de algunos infantes, los continuos problemas de conectividad y la poca duración de las sesiones. A veces, los cuarenta minutos resultaban insuficientes para completar las actividades diseñadas. Por consiguiente, había que habilitar nuevos enlaces de acceso gratuitos, esperar a que todo el alumnado volviera a conectarse 
y continuar con la videoconferencia. Evidentemente, este factor restó dinamismo a algunas sesiones.

- Como fortalezas, las estudiantes destacan: la participación y el apoyo de las familias, el interés de los pequeños hacia las actividades propuestas, la incorporación de la tecnología educacional en los procesos de enseñanza, la flexibilidad, libertad y autonomía en el diseño e implementación de las sesiones virtuales, el fomento de la creatividad y la imaginación, y el uso de la plataforma ZOOM como instrumento de investigación. Además, inciden en el hecho de que la experiencia ha resultado muy relevante para su formación como futuras docentes, "ya que ha supuesto un desafío real, acorde con las necesidades educativas que presentan los niños y las niñas del país" (frase extraída textualmente de una de las encuestas).

\section{Conclusiones}

El aislamiento social que se produjo como consecuencia del confinamiento decretado por el Gobierno del país dio lugar a que muchos niños y niñas de Ecuador dejaran de ver a sus compañeros de clase de un día para otro. En estas circunstancias, la única relación que los pequeños podían tener con sus iguales se hacía posible gracias al uso de la tecnología. Así pues, a pesar de las dificultades derivadas de la ausencia de presencialidad física, las evidencias presentadas a lo largo de estas páginas han demostrado que la educación sincrónica mediante videoconferencia puede ser un espacio para la cercanía y el diálogo, en consonancia con lo que afirman algunos estudios previos al respecto (Alatorre-Rojo et al., 2020; Atila, 2020; ChiñasPalacios et al., 2019).

Gracias a las sesiones virtuales diseñadas e implementadas por las estudiantes de la UNAE en el marco del proyecto IniciaTIC 2020, los infantes pudieron mantener el contacto diario con sus compañeros de clase y desarrollar progresivamente los objetivos educativos y las destrezas establecidas en el Currículo de Educación Inicial del Ecuador desde la seguridad de sus hogares. A su vez, las familias pudieron descargarse, al menos durante algunos momentos del día, del esfuerzo que conlleva ejercer el rol de padres/ madres y docentes al mismo tiempo.

Asimismo, cabe señalar que todos los actores involucrados directamente en el desarrollo de la práctica pedagógica aportaron e intercambiaron conocimientos y experiencias. Las estudiantes fueron guiadas por sus tutoras profesionales y pudieron encontrar utilidad a los conocimientos teóricos adquiridos a lo largo de la carrera; las tutoras profesionales, como 
contraparte, se beneficiaron del ingenio, la creatividad y el buen hacer de las estudiantes; y el profesorado universitario a cargo del noveno ciclo hizo las veces de nexo entre ambos colectivos y se constituyó como un equipo de trabajo bien cohesionado, demostrando que las acciones propuestas en el ámbito de sus respectivas asignaturas se orientaban hacia la consecución de una meta común: la construcción de la identidad profesional de las futuras docentes.

Como principal limitación encontrada durante el análisis de la experiencia, cabría señalar la dificultad por parte de los investigadores para desarrollar un proceso indagatorio que se planteaba en un entorno novedoso, en el que las variables eran emergentes y no podían preverse de antemano. Por otra parte, resultaba complicado desligar la función docente de la función investigadora, ya que ambas se desempeñaban simultáneamente durante la implementación del proyecto. Por este motivo, quizás hubiese sido conveniente contar con la figura de un evaluador externo que pudiera aportar una visión más objetiva de las acciones propuestas y contribuyera a ampliar el debate sobre las posibilidades formativas que encierra la realización de la práctica pedagógica en modalidad virtual.

En este sentido, también se abren algunas líneas futuras de trabajo si se plantea la posibilidad de replicar la experiencia con otro grupo de estudiantes y comparar los resultados obtenidos en contextos educativos diferentes, variando las temáticas abordadas o aspectos tales como la cantidad o duración de las sesiones. También sería muy enriquecedor conocer experiencias similares realizadas en otras universidades e intercambiar propuestas sobre cómo afrontar la práctica pedagógica en tiempos de pandemia. Para los autores del presente escrito, cualquier iniciativa que vaya destinada a mejorar las competencias profesionales de las estudiantes mediante el análisis y la reflexión de la propia práctica siempre será necesaria, independientemente del formato en el que se lleve a cabo. Por ello, consideramos pertinente continuar trabajando en la misma dirección.

Para terminar, una última reflexión: es indudable que el año 2020 ha marcado un antes y un después en todos los ámbitos. Y la educación, por supuesto, no iba a ser una excepción. Tal vez, en el futuro, la virtualidad se entienda como una parte indispensable de los procesos formativos, y las videoconferencias como la estrategia habitual para seguir manteniendo vivo el contacto entre el profesorado y su grupo de estudiantes. Aun así, si hay algo que la pandemia nos ha dejado claro es que la enseñanza presencial es insustituible en todos los niveles: desde educación inicial hasta estudios superiores. Por muchas ventajas que queramos encontrar a la docencia en línea (que tenerlas, las tiene), la realidad nos ha demostrado que los centros educativos son lugares donde el alumnado no solo acude para cursar 
asignaturas, aprender contenidos académicos y aprobar exámenes, sino, ante todo, para establecer relaciones humanas. Y esta es una lección que cualquier profesional de la educación no debería olvidar nunca. Esperemos que este escrito sirva para ello.

\section{Sobre los autores}

José Luis Del Río-Fernández es doctor en Ciencias de la Educación, máster en Políticas y Prácticas de Innovación Educativa y licenciado en Pedagogía. Actualmente es docente-investigador en la Universidad de Málaga, España, y profesor del Máster de Educación Inclusiva en la Universidad Nacional de Educación, Ecuador. Su línea de investigación es la formación del profesorado.

Álvarez, C. y San Fabián, J. L. (2012). La elección del estudio de caso en investigación educativa. Gazeta de Antropología, 28(1), artículo 14. http://hdl. handle.net/10481/20644

Angulo, F. y Vázquez, R. (Coords.). (2003). Introducción a los estudios de caso. Los primeros contactos con la investigación etnográfica. Aljibe.

Atila, J. D. (Coord.). (2020). Experiencias de la docencia universitaria en tiempos del Covid-19. Universidad Autónoma Gabriel René Moreno (UAGRM).

Beck, H. (2019). Errar es útil. Cuando equivocarse es acertar. Ariel.

Bisquerra, R. (2016). Metodología de la investigación educativa. La Muralla.

Bolívar, R. M. (2019). Investigar la práctica pedagógica en la formación inicial de maestros. Pedagogía y Saberes, 51, 9-22. https://doi.org/10.17227/pys. num51-2881

Cortés-González, P., González, B. y Padua D. (2020). Visiones del alumnado y el sentido del prácticum en educación primaria. Revista Interuniversitaria de Formación del Profesorado, 95(34.2), 275-298. https://doi.org/10.47553/ rifop.v34i2.79613

Chacón-Medina, A. (2003). La videoconferencia: conceptualización elementos y uso educativo. Revista EticaNet, 2, 1-13. https://www.ugr.es/ - sevimeco/ revistaeticanet/Numero2/Articulos/La\%20videoconferencia.pdf

Chavarría-Navarro, X., Hampshire, S. y Martínez, F. (2004). Una aproximación a los estudios de caso desde la práctica. Revista de Investigación Educativa, 22(2), 443-458. https://revistas.um.es/rie/article/view/98661 
Chiñas-Palacios, C., Vargas-Salgado, C., Águila-León J. y García, E. (2019). Zoom y Moodle: acortando distancias entre universidades. Una experiencia entre la Universidad de Guadalajara, México y la Universidad Libre de Colombia. En Actas del $V$ Congreso de Innovación Educativa y Docencia en Red (pp. 516-226). Universidad Politécnica de Valencia (UPV).

Cisterna-Cabrera, F. (2005). Categorización y triangulación como procesos de validación del conocimiento en investigación cualitativa. Theoria, 14(1), 61-71. https://www.redalyc.org/pdf/299/29900107.pdf

Crespo, M. y Palaguachi, M. (2020). Educación con tecnología en una pandemia: breve análisis. Revista Scientific, 5(17), 292-310. https://doi.org/10.29394/ Scientific.issn.2542-2987.2020.5.17.16.292-310

Davini, M.C. (2015). La formación en la práctica docente. Paidós.

Del Río-Fernández, J. L. (2021). La Lesson Study como estrategia formativa para aprender a enseñar en la universidad. Algunas reflexiones derivadas de un Proyecto de Innovación Educativa desarrollado en la Universidad Nacional de Educación (UNAE). Revista Complutense de Educación, 32(2), 171-180. https://doi.org/10.5209/rced.68205

Díaz-Quero, V. (2006). Formación docente, práctica pedagógica y saber pedagógico. Laurus, 12(Ext), 88-103. https://www.redalyc.org/pdf/761/76109906.pdf

Elliott, J. (2015). Lesson y Learning Study y la idea del docente como investigador. Revista Interuniversitaria de Formación del Profesorado, 84(29.3), 29-46. https://redined.mecd.gob.es/xmlui/bitstream/handle/11162/115 521/LasLessonYLearningStudiesYLaldeaDelDocenteComolnve.pdf?sequen $\mathrm{ce}=1$ \&isAllowed $=\mathrm{y}$

IESLAC (Instituto Internacional para la Educación Superior en América Latina y el Caribe). (2020). Covid-19 y educación superior: De los efectos inmediatos al día después. Análisis de impactos, respuestas políticas y recomendaciones. UNESCO.

IISUE (Instituto de Investigaciones sobre la Universidad y la Educación). (2020). Educación y pandemia. Una visión académica. UNAM.

Levy, D. (2020). ¿Cómo enseñar con Zoom? Una guía práctica para motivar a tus estudiantes y ayudarlos a aprender. Dan Levy.

López-Ramírez M. y Andrés-Rodríguez, S. (2020) Trayectorias escolares en la educación superior ante la pandemia, ¿continuar, interrumpir o desistir? En IISUE, Educación y pandemia. Una visión académica (pp.103-108). UNAM.

Marín-Suelves, D., Pardo-Baldoví, M. I., Vidal-Esteve, M. I. y San Martín-Alonso, Á. (2021). Indagación narrativa y construcción de identidades docentes: la reflexión pedagógica como herramienta de formación docente. Revista Electrónica Interuniversitaria de Formación del Profesorado, 24(2), 125-138. https://doi.org/10.6018/reifop.469691

Martínez-Carazo, P. (2006). El método del estudio de caso. Estrategia metodológica de la investigación científica. Pensamiento y Gestión, 20, 165-193. https://rcientificas.uninorte.edu.co/index.php/pensamiento/article/ view/3576

Okuda, M. y Gómez-Restrepo, C. (2005). Métodos en investigación cualitativa: triangulación. Revista Colombiana de Psiquiatría, 34(1), 118-124. http://www.scielo.org.co/scielo.php?script=sci_arttext\&pid=S0034-74502 005000100008 
Parra, L. R., Menjura, M. I., Pulgarín, L. E. y Gutiérrez, M. M. (2021). Las prácticas pedagógicas. Una oportunidad para innovar en la educación. Revista Latinoamericana de Estudios Educativos, 17(1), 70-94. http://latinoamericana. ucaldas.edu.co/downloads/Latinoamericana17(1)_5.pdf

Pérez-Gómez, Á. y Soto, E. (2011). Lesson Study. La mejora de la práctica y la investigación docente. Cuadernos de Pedagogía, 417, 64-68.

Pérez-Gómez, Á.I. (2012). Educarse en la era digital. Morata.

Rappoport, S., Rodríguez-Tablado, M. S. y Bresanello, M. (2020). Enseñar en tiempos de COVID-19. Una guía teórico-práctica para docentes. Oficina Regional de Ciencias de la UNESCO para América Latina y el Caribe.

Reinoso-González, E. (2020). La videoconferencia como herramienta de educación: ¿qué debemos considerar? Revista Española de Educación Médica, 1, 60-65. https://doi.org/10.6018/edumed.426421

Ruiz-Larraguivel, E. (2020). La práctica docente universitaria en ambientes de educación a distancia. Tensiones y experiencias de cambio. En IISUE, Educación y pandemia. Una visión académica (pp. 109-113). UNAM.

Sánchez-Mendiola, M. (2020). Involucrar a los estudiantes al usar Zoom [Archivo de video]. Revista Mexicana de Bachillerato a Distancia, 12(24). http://dx.doi. org/10.22201/cuaed.20074751e.2020.24.76818

Serhan, D. (2020). Transición del aprendizaje presencial al remoto: actitudes y percepciones de los estudiantes sobre el uso de Zoom durante la pandemia de COVID-19. Revista Internacional de Tecnología en Educación y Ciencia (IJTES), 4(4), 335-342. https://doi.org/10.46328/ijtes.v4i4.148

Soto-Gómez, E., Serván-Núñez, M. J., Trapero, N. P. y Pérez-Gómez, Á. I. (2019). Nuevos retos en la formación del profesorado. Lesson Study: acompañar la enseñanza y la investigación. Márgenes Revista de Educación de la Universidad de Málaga, 38-57. https://doi.org/10.24310/mgnmar.v0i0.6504

Stake, R. E. (2020). Investigación con estudio de casos. (6 $6^{a}$ ed.). Morata.

Trujillo-Sáez, F., Álvarez-Jiménez, D., Montes-Rodríguez, R., Segura-Robles, A. y García-San Martín, M. J. (2020). Aprender y educar en la era digital: marcos de referencia. ProFuturo.

Vera, F. (2021). Impacto de las plataformas de videoconferencia en la educación superior en tiempos de COVID-19. Revista Electrónica Transformar, 2(1), 41-57. https://revistatransformar.cl/index.php/transformar/article/view/8

Zabalza, M. A. (2017). El Prácticum y las prácticas externas en la formación universitaria. Revista Prácticum, 1(1), 1-23. https://doi.org/10.24310/RevPracti cumrep.v1i1.8254 